\title{
Use of a non-radioactive hybridisation assay for direct detection of gram-negative bacteria carrying TEM $\beta$-lactamase genes in infected urine
}

\author{
G. I. CARTER, K. J. TOWNER*, N. J. PEARSON and R. C. B. SLACK
}

\section{Department of Microbiology PHLS Laboratory, University Hospital, Nottingham NG7 2UH}

\begin{abstract}
Summary. DNA in infected urines from 81 patients with urinary tract infection was hybridised directly with a non-radioactive DNA probe specific for bacterial genes coding for TEM-type $\beta$-lactamase. The results were assessed by means of a computerised image analysis system and compared with those obtained following isolation of the infecting organism, conventional sensitivity testing and isoelectric focusing (IEF) procedures for the detection of TEM-type $\beta$-lactamase. Of the 27 ampicillin-resistant gram-negative organisms isolated in pure culture from the urines, 14 were shown by both hybridisation and IEF to carry a gene for TEM $\beta$-lactamase production. Only four discordant results were obtained: three "false positive" direct hybridisation results, one due to urine pigmentation, and one, possibly, to a TEM $\beta$ lactamase gene which was not being expressed, and one "false negative" result due to insufficient cell numbers in the urine. The system is capable of screening large numbers of samples and is applicable to any gene for which a suitable DNA probe is available.
\end{abstract}

\section{Introduction}

Nucleic acid hybridisation tests with specific gene probes have been used in various studies of the characterisation and spread of antibiotic resistance determinants (reviewed by Tenover, 1986). These tests offer the possibility of screening large numbers of samples for the presence of a particular resistance gene and, under certain circumstances, may have advantages over the conventional physical and biochemical tests used to characterise resistance gene products. Nucleic acid probes that hybridise specifically with the chromosomal or plasmid genes that encode particular resistance mechanisms demonstrate the potential for a microorganism to exhibit that resistance phenotype. DNA probe technology has been used primarily for epidemiological purposes and has provided information regarding dissemination of resistance genes and their evolutionary relationships. However, as such tests can be used to detect specific genes without primary isolation and growth of the organism, this technology has the potential for enabling direct detection of bacteria expressing certain types of resistance in crude clinical specimens.

Received 18 May 1988; accepted 4 Aug. 1988.

* Correspondence and requests for offprints should be sent to Dr K. J. Towner.
We have reported previously the development of a colourimetric non-radioactive spot hybridisation test which was capable of detecting a specific resistance gene in purified bacterial cells (Carter $e t$ al., 1987). Such colourimetric detection of hybridised sequences has many advantages over techniques incorporating radioactive labels, including probe stability, safety, acceptability, and rapidity of detection. We now report the extension of this work to include direct detection of resistant bacteria in urine samples. For the purpose of setting up a model detection system we formulated a hybridisation test for bacteria carrying genes coding for TEM-type $\beta$-lactamase. The synthesis of $\beta$-lactamase is the most important mechanism of resistance to $\beta$-lactam antibiotics in gram-negative bacteria and, of the many $\beta$-lactamases classified to date, the TEM class enzymes (TEM-1 and TEM-2) are the most prevalent types encoded by transmissible plasmids (Simpson et al., 1986).

\section{Materials and methods}

\section{Urine samples and bacteria}

Urine samples were obtained from a total of 81 randomly chosen patients with proven urinary tract infection. They were routine samples which had been submitted to the diagnostic microbiology laboratory, 
University Hospital, Nottingham and were only included in this study if subsequently shown by conventional techniques to contain a minimum of $10^{5} \mathrm{cfu} / \mathrm{ml}$. Portions $(0.1 \mathrm{ml})$ of neat urine were filtered on to hydrated nitrocellulose membranes (Schleicher and Schüll $\mathrm{GmbH}$, Postfach 4, 9-3354, Dassel FRG) by means of a $12 \times 8$ sample format BioDot microfiltration apparatus (BioRad Laboratories Ltd, Caxton Way, Watford, WD1 8RP). Cell lysis and denaturation of DNA for subsequent hybridisation were as previously described (Maniatis $e t$ al., 1982). Bacteria from the infected urines were isolated by a semi-quantitative technique on CLED agar (Oxoid CM303) and identified by standard bacteriological methods. Purified cultures were screened for resistance to ampicillin (MIC $\geq 10 \mathrm{mg} / \mathrm{L}$ ) by conventional breakpoint susceptibility tests. Overnight nutrient-broth cultures of the purified bacteria were also diluted in sterile saline to a cell density of $c .3 \times 10^{7} \mathrm{cfu} / \mathrm{ml}$ and filtered on to nitrocellulose as described above.

Control strains used in this study were a plasmid-free strain of Escherichia coli $\mathrm{K} 12 \mathrm{~J} 53.2$ and the same strain carrying plasmid pBR322 (coding for TEM-1 $\beta$-lactamase).

\section{Hybridisation test}

The DNA probe consisted of a $998 \mathrm{bp}$ EcoRI/HinfI fragment of pBR322 incorporating a large region of the TEM-1 $\beta$-lactamase gene (Cooksey et al., 1985). The probe was isolated, purified and labelled with biotin-11dUTP as described previously (Carter $e t$ al., 1987). The probe concentration used was approximately $0 \cdot 1 \mu \mathrm{g} / \mathrm{ml}$ of hybridisation solution $\left(0.1 \mathrm{ml}\right.$ of solution $/ \mathrm{cm}^{2}$ of nitrocellulose membrane). Pre-treatment of membranes with proteinase $\mathrm{K}$ and subsequent hybridisation procedures were as described previously (Carter et al., 1987). Detection of hybridisation was by means of a BluGENE Detection System (Gibco/BRL Ltd, 3, Washington Road, Paisley PA3 4EP) with the conditions and washes recommended by the manufacturer. The final colourimetric reaction was terminated $2 \mathrm{~h}$ after addition of the

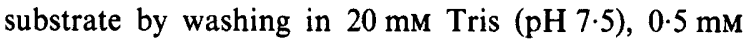
$\mathrm{Na}_{2}$ EDTA.

\section{Automated reading of hybridisation results}

The colour intensity generated in hybridisation experiments was read by a computer-controlled image analysis system (Mastascan 2; Mast Laboratories Ltd, Mast House, Derby Road, Bootle, Merseyside, L20 1EA). This system was originally designed to read multipoint inoculated antibiotic susceptibility tests, but was easily modified to read the membranes in the $12 \times 8$ sample format produced by the BioDot microfiltration apparatus. The membranes were held in position by a specially constructed base-plate and new software was written to allow the intensity of each spot to be read internally in a $3 \times 3$ matrix. Compensation was made for any variation in the staining intensity of the membrane or of illumina- tion by computing the average of the nine internal readings minus the average of four external readings taken around each spot. The system thereby generated a digital value corresponding to the intensity of the hybridisation signal at each position.

\section{Analytical isoelectric focusing (IEF)}

Purified bacterial isolates were grown in $30 \mathrm{ml}$ of nutrient broth at $37^{\circ} \mathrm{C}$ overnight on an orbital shaker. The cells were pelleted by centrifugation, resuspended in $2 \mathrm{ml}$ of $0.02 \mathrm{M}$ phosphate buffer $(\mathrm{pH} \mathrm{7.2)}$ and disrupted by a PG-100 ultrasonicator (MSE Scientific Instruments, Manor Royal, Crawley, Sussex RH10 2QQ) for four 15-s bursts at an amplitude of $15 \mu \mathrm{m}$. Cell debris was removed by centrifugation $(12000 \mathrm{~g}, 5 \mathrm{~min})$ and IEF was performed on the crude enzyme extracts by the cellulose acetate membrane method described by Eley et al. (1983). When necessary, the $\beta$-lactamase extracts were concentrated 20 -fold by freeze-drying. The isoelectric point (pI) of each $\beta$-lactamase band was first determined over the $\mathrm{pH}$ range $3.5-10.0$ by comparison with a mixture of protein markers of known pI (range 4.7-10.6; BDH Ltd, Broom Road, Poole, Dorset BH12 4NN). When the enzymes focused in the range pI 5-6, a more precise determination was made by use of a narrow range of ampholytes (pH 4-6) and a direct comparison with known TEM enzymes.

\section{Results}

\section{Reproducibility of results generated by the hybridisation system}

The reproducibility of the Mastascan system was tested by repeated screening of duplicate blots of the positive and negative control strains. With a standard broth inoculum (Carter et al., 1987) of $3 \times$ $10^{6}$ cells $/ 100-\mu \mathrm{l}$ spot, the positive controls generated a mean reading of 34.2 units $(n=32$; SD 5.6), whereas the negative controls gave a mean "background" reading of 3.7 units $(n=32 ; \mathrm{SD} 1 \cdot 8)$. These results showed that the system was able to distinguish a positive hybridisation result with broth cultures. Treatment of filters with proteinase $K$ before hybridisation was, however, an essential step. If this was omitted, all samples gave an apparently positive hybridisation signal, possibly due to non-specific binding of the streptavidine component of the detection system to endogenous bacterial protein.

\section{Application of the system to urine samples}

Non-infected urine was artificially contaminated with different cell concentrations of $E$. coli $\mathrm{J} 53 \cdot 2$ or 
J53.2(pBR322) and probed as described in Methods. Results were compared with those obtained with the same cell concentrations in sterile saline. The figure shows that the intensity readings obtained with strain $\mathrm{J} 53.2$ were low when the organism was applied in either urine or saline, with only slightly elevated readings at cell densities exceeding $5 \times 10^{6}$ cells/spot. The strain carrying pBR322 (encoding the TEM-1 $\beta$-lactamase) could be easily distinguished at cell densities $\geq 10^{5}$ cells/spot. The application of cells in either urine or saline did not affect the results significantly.

\section{Hybridisation studies with infected urines}

A hybridisation intensity signal was measured for each of the 81 infected urines tested. The results were compared with those obtained after isolation of the infecting organism, followed by conventional sensitivity tests, and are summarised as follows:

(i) A total of 26 urines was infected with an ampicillin-sensitive strain of E. coli. Each of these urines showed little or no reaction with the TEM probe, generating a mean signal intensity of 2.5 units (SD 1.9 units; range 0-6 units). From these results, the "cut-off" point between a negative and a positive hybridisation result was defined as $\mathbf{8 \cdot 2}$ units (3 SD above the mean).

(ii) According to the above criterion, 20 urines generated a positive signal with the TEM probe. Three of these urines yielded mixed cultures and were not investigated further. An ampicillinresistant gram-negative organism was isolated from each of the remaining 17 urines. Results obtained with these 17 organisms are shown in the table.

(iii) The remaining 35 urines gave negative results with the probe by the above definition. Seven of these urines yielded either mixed cultures or gram-positive bacteria. From the remaining 28 urines, 18 ampicillin-sensitive gram-negative organisms (other than $E$. coli) and 10 ampicillin-resistant gram-negative organisms were isolated. Results obtained with these 10 ampicillin-resistant probenegative organisms are also shown in the table.

Apart from the few exceptions described in the next section, results obtained by hybridisation with diluted nutrient-broth cultures of the purified organism were compatible with those obtained by direct hybridisation with the crude urine sample.

\section{IEF studies on ampicillin-resistant isolates}

To test the validity of the hybridisation test, crude $\beta$-lactamase extracts were prepared from
Table. Comparison of the results obtained by IEF and hybridisation methods with ampicillin-resistant gramnegative bacteria

\begin{tabular}{|c|c|c|c|c|}
\hline \multirow[b]{2}{*}{ Organism } & \multirow{2}{*}{$\begin{array}{c}\text { Strain } \\
\text { no. }\end{array}$} & \multicolumn{2}{|c|}{$\begin{array}{l}\text { Hybridisation } \\
\text { intensity* in }\end{array}$} & \multirow{2}{*}{$\begin{array}{l}\text { Enzyme } \\
\text { pI value }\end{array}$} \\
\hline & & Urine & Broth & \\
\hline \multirow[t]{13}{*}{ Escherichia coli } & 14 & $32(+)$ & $36(+)$ & $5 \cdot 4$ \\
\hline & 19 & $14(+)$ & $2(-)$ & $6 \cdot 7$ \\
\hline & 36 & $42(+)$ & $34(+)$ & $5 \cdot 4$ \\
\hline & 39 & $23(+)$ & $23(+)$ & $5 \cdot 4$ \\
\hline & 41 & $43(+)$ & $40(+)$ & $5 \cdot 4$ \\
\hline & 44 & $33(+)$ & $46(+)$ & $5 \cdot 4$ \\
\hline & 51 & $19(+)$ & $41(+)$ & $5 \cdot 4$ \\
\hline & 54 & $26(+)$ & $46(+)$ & $5 \cdot 4$ \\
\hline & 66 & $10(+)$ & $39(+)$ & $5 \cdot 4$ \\
\hline & 67 & $6(-)$ & $32(+)$ & $5 \cdot 4$ \\
\hline & 85 & $24(+)$ & $18(+)$ & $5 \cdot 4$ \\
\hline & 86 & $29(+)$ & $40(+)$ & $5 \cdot 4$ \\
\hline & 91 & $9(+)$ & $31(+)$ & $5 \cdot 4$ \\
\hline \multirow[t]{8}{*}{ Klebsiella spp. } & 7 & $8(-)$ & $0(-)$ & - \\
\hline & 11 & $5(-)$ & $0(-)$ & $7 \cdot 5$ \\
\hline & 26 & $4(-)$ & $0(-)$ & $5 \cdot 5$ \\
\hline & 32 & $50(+)$ & $0(-)$ & $6 \cdot 7$ \\
\hline & 65 & $1(-)$ & $0(-)$ & $7 \cdot 4$ \\
\hline & 72 & $19(+)$ & $28(+)$ & $7 \cdot 5$ \\
\hline & 81 & $31(+)$ & $56(+)$ & $5 \cdot 4$ \\
\hline & 96 & $1(-)$ & $1(-)$ & $7 \cdot 4$ \\
\hline \multirow[t]{3}{*}{ Proteus spp. } & 15 & $27(+)$ & $52(+)$ & $5 \cdot 4$ \\
\hline & 58 & $3(-)$ & $0(-)$ & - \\
\hline & 63 & $34(+)$ & $43(+)$ & $5 \cdot 4$ \\
\hline Pseudomonas & 49 & $4(-)$ & $0(-)$ & $8 \cdot 0$ \\
\hline \multirow[t]{2}{*}{ aeruginosa } & 60 & $1(-)$ & $0(-)$ & $5 \cdot 3$ \\
\hline & 71 & $5(-)$ & $0(-)$ & - \\
\hline
\end{tabular}

* Hybridisation intensities are expressed in arbitrary units generated by the computerised image analysis system. $+=$ Positive result $;-=$ negative result.

each of the ampicillin-resistant organisms listed in the table and a pI value determined for each $\beta$ lactamase enzyme detected.

Of the 17 probe-positive strains, 14 produced an enzyme which focused at the position expected for TEM-1 (pI 5.4). Three exceptions were detectedstrains 19,32 and 72 . These organisms were grown in nutrient broth, diluted in sterile saline to a density of $3 \times 10^{7}$ cells $/ \mathrm{ml}$ and the hybridisation test repeated. Strains 19 and 32 were probe-negative when grown in broth culture, but strain 72 continued to give a positive probe reaction (see Discussion).

Of the ten ampicillin-resistant probe-negative organisms, one strain of $E$. coli (strain 67) produced a $\beta$-lactamase with a pI value of 5.4 (=TEM-1). When this strain was grown subsequently in broth culture it gave a positive hybridisation result. Another two strains (26 and 60) produced $\beta$ lactamases with pI values similar to TEM-1 (pI 5.5 


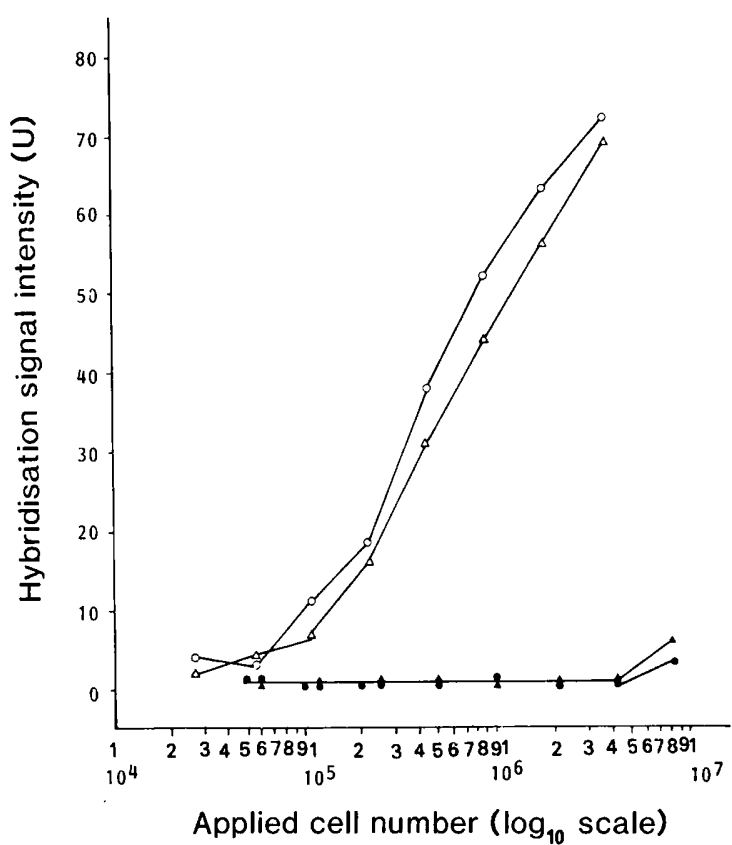

Figure. Hybridisation signal intensities (expressed in arbitrary units generated by the image analysis system) obtained after hybridisation of the TEM probe with the positive and negative control strains : $\longrightarrow$ strain J53.2 in saline; $\mathbf{\Delta}-\mathbf{\Delta}$ strain $\mathrm{J} 53.2$ in urine; $\mathrm{O}-\mathrm{O}$ strain $\mathrm{J} 53.2$ (pBR322) in saline; $\triangle \longrightarrow \triangle$ strain J53.2 (pBR322) in urine.

and $5 \cdot 3$ respectively), but subsequent hybridisation tests on broth cultures also generated negative results. It was concluded, therefore, that these strains produced $\beta$-lactamases which, although they had similar $\mathrm{pI}$ values, were different from TEM-1 and would not be expected to react with the probe.

\section{Discussion}

In this study we have shown that non-radioactive hybridisation assays can be used successfully to detect the presence of gram-negative bacteria producing the TEM-1 $\beta$-lactamase in urine. When compared with results by conventional methods, only four anomalous results were detected. Three "false-positive" results were obtained. E. coli strain 19 was isolated from a heavily pigmented urine sample, which gave a positive direct hybridisation result, whereas the same strain grown in broth culture was probe-negative. It seems, therefore, that the pigmentation of the urine was of sufficient intensity to be read as probe-positive by the Mastascan system. Klebsiella strain 32 produced similar results, but with no obvious pigmentation in the urine. We have no explanation for this anomaly except to suggest that the original urine could have been infected by a second TEMproducing organism which was not detected on primary isolation. In the third "false-positive" result, Klebsiella strain 72 generated a positive hybridisation result in both urine and broth culture, but we were unable to identify a TEM-type $\beta$ lactamase in this organism. It seems that either the gene encoding the resistance enzyme in strain 72 had sufficient homology with the TEM probe to generate a positive hybridisation result, or that there was a "silent" non-expressed TEM $\beta$-lactamase gene present in the genome of this strain. Similar results have been reported by other authors (Jouvenot et al., 1987). Only one "false-negative" result was obtained in which a urine gave a negative hybridisation result but the strain isolated was found subsequently to produce a TEM $\beta$-lactamase. This strain ( $E$. coli strain 67 ) gave a positive hybridisation result when grown in broth culture and the original negative result may have been due to the presence of insufficient cells in the original urine for detection (the detection limit for the test is $10^{5}$ cells $/ \mathrm{spot}$, or $10^{6}$ cells $/ \mathrm{ml}$ urine, but the urines were originally defined as "infected" if they contained $10^{5}$ cells $/ \mathrm{ml}$ urine).

Several previous studies have used radioactivelylabelled DNA probes to test for the presence of TEM $\beta$-lactamase genes in pure cultures of bacteria (Murphy-Corb et al., 1984; Cooksey et al., 1985; Jouvenot et al., 1987; Ouellette et al., 1987). A similar probe was used by Perine et al. (1985) to detect penicillinase-producing Neisseria gonorrhoeae directly in urethral exudates from males. We have shown in this study that DNA hybridisation incorporating a non-radioactive biotin-based detection system can be combined with a computerised image analysis system to detect resistant gramnegative bacteria directly in infected urine. Automated image analysis allows the hybridisation signal to be quantified and a large number of clinical samples to be processed rapidly. The procedure is suitable for use in laboratories that lack the facilities or expertise to handle highlyradioactive materials and could be adapted for any antibiotic resistance gene for which a suitable DNA probe is available.

DNA probes have been used successfully to identify a wide variety of pathogens (reviewed by Tenover, 1988), including infectious agents that are either difficult or impossible to culture in vitro. We have shown in this study that it is possible to detect bacteria carrying specific antibiotic-resistance genes directly in infected urine. In a similar manner, DNA probes can be used to detect specific pathogens directly in clinical specimens and hence, 
particularly with fastidious pathogens, significantly reduce the time and overall costs required for processing specimens. Commercial kits are already being produced and it is likely, therefore, that DNA

\section{REFERENCES}

Carter G I, Towner K J, Slack R C B 1987 Detection of TEM beta-lactamase genes by non-isotopic spot hybridisation. European Journal of Clinical Microbiology 6: 406-409.

Cooksey R C, Clark N C, Thornsberry C 1985 A gene probe for the TEM type $\beta$-lactamases. Antimicrobial Agents and Chemotherapy 28: 154-156.

Eley A, Ambler J, Greenwood D 1983 Isoelectric focusing of beta-lactamases on cellulose acetate membranes. Journal of Antimicrobial Chemotherapy 12: 193-196.

Jouvenot M et al. 1987 Molecular hybridization versus isoelectric focusing to determine TEM-type $\beta$-lactamases in gramnegative bacteria. Antimicrobial Agents and Chemotherapy 31: $300-305$.

Maniatis T, Fritsch E F, Sambrook J 1982 Molecular cloning : a laboratory manual. Cold Spring Harbor Laboratory, Cold Spring Harbor, New York, p 314.

Murphey-Corb M, Nolan-Willard M, Daum R S 1984 Integration of plasmid DNA coding for $\beta$-lactamase production in probes will have an increasing impact on all clinical microbiology laboratories.

This work was supported by a research grant from the Trent Regional Health Authority.

the Haemophilus influenzae chromosome. Journal of Bacteriology 160: 815-817.

Ouellette M, Rossi J J, Bazin R, Roy P H 1987 Oligonucleotide probes for the detection of TEM-1 and TEM-2 betalactamase genes and their transposons. Canadian Journal of Microbiology 33: 205-211.

Perine P L et al. 1985 Evaluation of a DNA-hybridization method for detection of African and Asian strains of Neisseria gonorrhoeae in men with urethritis. Journal of Infectious Diseases 152: 59-63.

Simpson I N, Knothe H, Plested S J, Harper P B 1986 Qualitative and quantitative aspects of $\beta$-lactamase production as mechanisms of $\beta$-lactam resistance in a survey of clinical isolates from faecal samples. Journal of Antimicrobial Chemotherapy 17: 725-737.

Tenover F C 1986 Studies of antimicrobial resistance genes using DNA probes. Antimicrobial Agents and Chemotherapy 29: 721-725.

Tenover F C 1988 Diagnostic deoxyribonucleic acid probes for infectious diseases. Clinical Microbiology Reviews 1: 82-101. 